\title{
$1 \quad$ Is there any Non-functional Training? A Conceptual Review
}

2 Bernardo N. Ide ${ }^{1}$, Amanda P. Silvatti ${ }^{2}$, Moacir Marocolo ${ }^{3}$, Clarcson P. C. Santos ${ }^{4}$, Bruno

3 V. C. Silva ${ }^{5}$, Dustin J. Oranchuk ${ }^{6}$, Gustavo R. Mota*1.

$4{ }^{1}$ Exercise Science, Health and Human Performance Research Group, Department of Sport

5 Sciences, Institute of Health Sciences, Federal University of Triângulo Mineiro, Uberaba, MG,

6 Brazil. ${ }^{2}$ Department of Physical Education, Federal University of Viçosa, Viçosa, MG, Brazil.

$7 \quad{ }^{3}$ Physiology and Human Performance Research Group, Department of Physiology, Federal 8 University of Juiz de Fora, Juiz de Fora, MG, Brazil. ${ }^{4}$ Research Group on Metabolic Diseases, 9 Physical Exercise and Health Technologies, Bahiana School of Medicine and Public Health,

10 BA, Brazil. ${ }^{5}$ University Center of Belo Horizonte, Belo Horizonte, MG, Brazil. ${ }^{6}$ Sports

11 Performance Research Institute New Zealand, Auckland University of Technology, Auckland,

12 New Zealand.

$13 *$ Correspondence:

14 gustavo.mota@uftm.edu.br

\section{Abstract}

16 This conceptual review aimed to investigate whether "functional training" (FT) programs are 17 different from traditional strength, power, flexibility, and endurance training programs. A 18 search for the twenty most recent papers published involving FT was performed in the 19 PubMed/Medline database. Definition, concepts, benefits, and the exercises employed in FT 20 programs were analyzed. The main results were: 1) there is no agreement about a universal 21 definition for FT; 2) FT programs aim at developing the same benefits already induced by 22 traditional strength, power, flexibility, and endurance training programs; 3) exercises employed are also the same. The inability to define FT makes differentiation difficult. Physical training programs can be easily described and classified as strength, power, flexibility, endurance, and the specific exercises employed (e.g., traditional resistance training, ballistic exercises, plyometrics and Olympic-style weightlifting, continuous and high-intensity interval training). This proper description and classification may improve communication in sports science and improve interdisciplinary integration. Aiming to avoid confusion and misconceptions, and based on the current evidence, we recommend that the terms FT, high-intensity FT, and functional fitness training no longer describe any physical training program.

31 Keywords: core training, exercises, flexibility, fitness, periodization. 


\section{ORCID:}

33 Bernardo N. Ide - https://orcid.org/0000-0003-4057-0051

34 Amanda Piaia Silvatti - https://orcid.org/0000-0001-8781-8558

35 Moacir Marocolo - https://orcid.org/0000-0002-7715-2534

36 Clarcson P. C. Santos - https://orcid.org/0000-0001-7598-3775

37 Bruno V. C. Silva - https://orcid.org/0000-0002-4509-937X

38 Dustin J. Oranchuk - http://orcid.org/0000-0003-4489-9022

39 Gustavo R. Mota - https://orcid.org/0000-0002-6109-0658 


\section{$401 \quad$ Introduction}

41 Exercise adaptations are highly dependent on the specific training stimulus (1-3). Therefore,

42 an apt description of physical training programs is essential for planning neuromuscular,

43 cardiovascular, metabolic, and functional exercise performance and recovery enhancements.

44 Force, work, and power represent the basic mechanical concepts used in describing muscular

45 activity, function, and the classification of training stimuli/programs $(4,5)$.

46 Strength is defined as the force that can be developed by the muscles performing a particular

47 joint movement (e.g. elbow flexion, knee extension) (6). Work is expressed when the point of

48 application of the force moves through displacement (6), and power is the rate of performing

49 work; the derivative of work concerning time; the product of force and velocity (6). In addition,

50 muscles can maintain either a specific isometric force, or power level, involving combinations

51 of concentric and eccentric muscular actions, a functional property connoted as endurance (4).

52 Flexibility refers to the intrinsic property of body tissues determinant of range of motion

53 achievable without injury (7).

54 Strength, power, endurance and flexibility are well-defined concepts within exercise 55 prescription and muscle performance (8-10), nutritional requirements (11) and the study of 56 specific neuromuscular, cardiovascular, and metabolic adaptations $(2,9,12)$. Strength and 57 power training encompass short-duration activities performed at high- or near maximal 58 intensities, increasing the capacity to perform high-force, and high-velocity efforts $(1,12)$.

59 Exercises employed in these programs involve traditional resistance training, ballistic 60 exercises, plyometrics and Olympic-style weightlifting (8). On the other hand, endurance

61 training encompasses exercises performed at various intensities, lasting for several minutes up

62 to hours (13), increasing the capacity to sustain repetitive high and low-intensity efforts (9),

63 encompassing the application of continuous and high-intensity interval training methods (9). 
64 Endurance training covers exercises performed at various intensities, lasting for several

65 minutes up to hours (13), increasing the capacity to sustain repetitive high and low-intensity

66 efforts (9). Both continuous and distinct variations of high-intensity interval training (HIIT)

67 can be prescribed $(9,14)$

68 Otherwise, despite these well-consolidated characterizations of sports physical demand,

69 training programs designs and adaptations, a recently increasing number of articles introduce

70 apparently "new" physical training programs. Among sports scientists, it is common to hear

71 from students, coaches, and athletes: "I'm working with functional training (FT)," "I'm

72 engaged on a high-intensity FT program," "I'm investigating the neuromuscular responses to

73 functional training." These statements caught our attention and have been criticized properly

$74(15,16)$. Recently we have raised issues regarding the concepts and definition of FT (15).

75 Unfortunately, we found inconsistencies and misconceptions on the FT definition, cited

76 references that do not support the statements, and no differences regarding benefits and training

77 methods already used in sports training (15).

78 Considering that the dissemination of inconsistent concepts and definitions can induce

79 irreparable professional conduct and poor academic background, the present conceptual review

80 aimed to investigate whether FT programs are different from traditional strength, power,

81 flexibility, and endurance training programs. We hypothesized that there is no universal

82 definition for FT, and that these programs aim at developing the same adaptations already

83 present in strength, power, flexibility, and endurance training programs. FT exercises/training

84 methods are also the same already employed in athletes' training programs.

\section{Materials and Methods}

86 To attend to the purposes of the conceptual review study, we performed a non-exhaustive

87 search for the twenty most recent papers published about FT present in PubMed/Medline 
88 database. The search was completed in April 2021. The article's reference list was consulted

89 for additional definitions. The heterogeneity of the studies was considerable (e.g., exercise

90 protocols, fitness level of the participants, variables measured). Thus, we have decided not to

91 evaluate the studies from a statistical point of view. Instead, we performed a qualitative

92 analysis, focusing on the FT definitions, exercises employed, and benefits reported by the

93 authors. All other authors read this qualitative analysis carefully, and edits have been

94 incorporated.

\title{
$953 \quad$ Results
}

96 Examining the search results, we found additional FT "variations" (e.g., high-intensity FT, and

97 functional fitness), that were included in the analysis of definitions, benefits and exercises

98 employed. In addition to the articles, three textbooks were included (17-19).

$99 \quad 3.1 \quad$ Functional training definitions

100 Tables 1, 2 and 3 present the FT, high-intensity FT (HIFT), and functional fitness (FF)

101 definitions, respectively.

Please, Insert Table 1 About Here

103

Please, Insert Table 2 About Here

104

\author{
Please, Insert Table 3 About Here
}

105

\subsection{Functional training adaptations}

106 The adaptations/benefits proposed by each training program were extracted from the

107 definitions and additional descriptions presented in the articles. Tables 4,5 and 6 present the

108 FT, HIFT, and FF adaptations/benefits. 
112 Figure 1 presents a summary of the adaptations/benefits induced by FT, HIFT and FF training 113 programs.

\title{
$115 \quad 3.3 \quad$ Functional training exercises
}

116 The description of exercises employed in FT programs was extracted from the definitions

117 present and consulting the training protocols described in the methods section. Tables 7, 8 and

1189 present the FT, HIFT, and FF exercises employed.

119

Please, Insert Table 7 About Here

120

\author{
Please, Insert Table 8 About Here
}

121

Please, Insert Table 9 About Here

122 Figure 2 presents a summary of the exercises/training methods employed in FT, HIFT and FF

123 training programs. 


\section{Discussion}

126 The objective of this study was to investigate whether FT programs are different than

127 traditional strength, power, flexibility, and endurance training programs. The main results

128 were: 1) there is no agreement about a universal definition for FT (see Table 1); 2) FT programs

129 aim at developing the same adaptations already present in traditional training programs (see

130 Tables 4, 5, 6 and Fig. 1); 3) exercises employed are also basically the same (see Tables 7, 8,

1319 and Fig. 2). Our main finding is that the FT is not different from traditional strength, power,

132 and endurance training, therefore, corroborating our hypothesis.

133 Although muscle strength, power, flexibility, and endurance are well-defined concepts used in

134 exercise prescription $(4,6,8,9,12,20)$, FT problems arise in the following domains:

135 1. FT involves resistance training (21). Thus, it could be defined as resistance training.

1362 2. FT is related to developing different physical capacities in an "integrated and balanced

137 manner" (22). The interference phenomenon with concurrent training presents

138 attenuated muscle strength and mass gains compared to strength and power alone (23).

139 Thus, how does FT provide different physical capacities in an "integrated and balanced

140 manner"? Additionally, the authors (22) did not provide any scientific data to support

141 "an integrated and balanced" development of different physical capacities.

142 3. Strength exercises combined with endurance exercises could be described as 143 "combined", or "concurrent training". Therefore, there is no need to "create" new 144 terminology (i.e., FT) containing inconsistencies (15).

145 4. FT programs aim at an increase in efficiency and safety during activities related to daily 146 living, work, and sports (22); all these benefits are already well-related to the practice 147 of traditional training programs $(2,3,8,11,12,14)$. Thus, it is not an exclusive or 148 differentiating characteristic of FT programs per se (15). 
149

150

151

5. HIFT was defined as typically involving high-volume and high-intensity exercises, with short rest intervals using of multiple joint exercises (24). This definition consists of a basic description of a strength, power and endurance session adopted as a part of the preparation of elite athletes in specific phases of periodization $(20,25,26)$.

6. FF has defined a trend toward using strength training $(22,27)$. Thus, it could be easily described as a strength training program.

7. FF was stated to be also known as HIFT (28). Thus, FF is HIFT.

8. The difference found between FT and HIFT programs is inconsistent. Since exercise intensity is a training variable and not an exercise type, it would be expected that FT and HIFT were defined as the same training program performed with different intensities only. It was surprising to verify that they are considered separate entities.

Some of the FT problems stated above were previously highlighted (15), but we considered them pertinent to highlight again.

Muscular fitness is composed of the functional parameters of strength, endurance, and power, and each improves consequence to an appropriately designed resistance training regimen (29).

The definition of physical fitness implies an optimal combination of physical, physiological, biochemical, biomechanical and psychological characteristics that contribute to competitive success in sports (30). The physical fitness of an athlete is usually particular to a given class of competition (30), and each component of physical fitness (e.g., cardiorespiratory, muscular strength and endurance, body composition, flexibility, and neuromotor fitness) conceivably influences some aspect of health (29). In this context, both FF definitions found $(27,28)$ are not in agreement with the American College of Sports Medicine position stand (29), which states that FF training incorporates motor skills such as balance, coordination, gait, agility, and proprioceptive training, with physical activities such as tai ji (tai chi), qigong, and yoga (29). 
173 Another inconsistency in the FF definition was the use of the expression extreme conditioning

174 program (28). If the adjective "extreme" is employed to classify these programs, what kind of

175 adjective should we use to classify the physical training programs performed by elite athletes

176 of wrestler, soccer, football, rugby, basketball, mixed martial arts, triathletes, marathonists, and

177 track and field athletes, among others? We are conscious that physical training programs

178 promoted by some fitness companies (e.g., CrossFit ${ }^{\circledR}$, Insanity ${ }^{\circledR}$, Gym Jones $^{\circledR}$, and P90X ${ }^{\circledR}$ )

179 were previously classified as extreme conditioning programs (24). They are defined as

180 typically involving high-volume and high-intensity exercises, with short rest intervals and

181 multiple joint exercises (24). Some include variations of the Olympic-style weightlifting and

182 high-intensity interval training, plyometrics, and ballistic exercises (24). Nevertheless, this

183 training configuration is not exclusive, as it has already been adopted as a part of training

184 programs of elite athletes in specific phases of periodization (20). Additionally, High global

185 performance cited as an objective of FF program (28) represents an extremely vague and 186 inconsistent adaptation.

187 The main confusion about all these "new" training programs (i.e., FT, HIFT and FF) is that

188 they aim at neuromuscular adaptations that could be easily defined as strength, power, 189 endurance, and flexibility programs (see Tables 4, 56 and Fig 1). Functional 190 movements/exercises/activities are often cited as training stimuli, but the non-functional 191 movements are not defined. To the best of our knowledge, there is also no concise definition 192 of functional movements as well. By the way, is there any non-functional movement performed 193 from skeletal muscles?

194 Regarding FT adaptations/benefits, a particular concern was placed in the study of McLaughlin 195 et al. (31), where gait, balance, and FT were considered as different training interventions. In 196 their study (31), an overview of systematic reviews examined the effect of Balance and FT on 
197 health outcomes in adults aged 18 years or older. The authors concluded that balance and FT

198 reduced the rate of falls and the number of people who fell and improved physical functioning

199 and physical activity in healthy community-dwelling adults aged 65 years and older (31). This

200 separation observed of training interventions to improve gait and balance from FT reinforces

201 FT definitions' confusions, inconsistencies, and weaknesses.

202 FT, HIFT, and FF training programs present several similarities to those already used for elite

203 athletes for several decades $(8,25,26,29,32)$. Among them were high-volume and high-

204 intensity exercises, with short rest intervals using multiple joint exercises (24) and variations

205 of the Olympic-style weightlifting, high-intensity interval training, plyometrics and ballistic

206 exercises (24). All these exercises are also employed in the physical training of professional

207 athletes and recommended for developing and maintaining the cardiorespiratory,

208 musculoskeletal, and neuromotor fitness of healthy adults and the elderly $(8,25,26,29,32)$.

209 One of the definitions states that FT uses strength exercises aimed at improving core stability

210 (22). Curiously, a systematic review about the most effective exercises to stimulate the activity

211 of the core muscles (33) concluded that free weight exercises (squat and deadlift) are optimal

212 to achieve this goal and that performing floor exercises, adding balls/devices appears to be

213 unnecessary and not recommended (33). The systematic review results (33) reinforce that if

214 one of the objectives of FT is to improve core stability, traditional strength and power exercises

215 are the most efficient.

216 Curiously, one paper provides an equivocal separation of traditional resistance training and FT

217 (34). Traditional resistance training was considered as a conservative training method that uses

218 resistance machines with gradual, progressive load increases (34), and FT as combining multi-

219 planar, coordinated and multi-articular movements, organized according to movement patterns

220 such as squat, pushing, pulling and transporting in blocks that stimulate power, speed, stability 
221 or maximum strength. Considering that all these exercises are often employed in athletes'

222 strength and power training, there is no rationality in separating traditional from FT.

223 Indeed, the term FT originated in sports medicine and, more specifically, in rehabilitation 224 clinics (35). Early definitions focused on rehabilitation to enhance or develop the skills 225 associated with activities of daily living and, frequently, involving older adults (35). In this 226 context, the desired outcome is to restore (or rehabilitate) neuromuscular function. Guidelines 227 and arguments for implementing FT for back pain prevention are essentially the same for back 228 pain rehabilitation (16). This is because the "functional" status of rehabilitation exercises is 229 related to the activities and functions of the body and contextual factors such as environmental 230 and personal factors (36). Although, strength and conditioning professionals are constantly 231 working to improve a specific neuromuscular function. Therefore, the term FT becomes 232 redundant and confused (15).

233 Fleck and Kraemer (17) proposed that the general definition of FT is the training that is meant

234 to increase performance in some type of functional tasks, such as activities of daily living or 235 tests related to athletic performance (17). Thus, FT could refer to virtually any training meant 236 to increase motor performance (17). Considering that in exercise physiology, muscle strength, 237 power, flexibility, and endurance are often regarded as functional aspects of the neuromuscular 238 system, this general definition (17) appears to be the most rational.

\section{$2395 \quad$ Conclusions}

240 The current data show that FT programs are not different from those traditional training

241 programs already used in sports training, and there is no consistent universal definition for FT.

242 Also, the claimed FT's adaptations are the same biological adaptations induced by traditional

243 training programs (e.g., strength, endurance), as well as the "functional movements" are 244 already employed in the physical training plan of professional, recreational athletes, healthy 
245 adults, and the elderly. In other words: There is no "non-functional" training. Therefore, there

246 is no rationale in classifying exercise training programs as FT. Insisting in the use of this term

247 (i.e., FT) it is a classic case of needlessly reinventing the wheel (15).

\section{$248 \quad 6 \quad$ Future Recommendations}

249 Based on the current results, we recommend that the terms functional training, high-intensity

250 functional training, and functional fitness no longer describe any physical training program.

251 These can be easily classified as strength, power, endurance, flexibility, and described

252 according to the specific exercises employed (e.g., traditional resistance training, ballistic

253 exercises, continuous and high-intensity interval training), improving communication and

254 interdisciplinary integration.

255 Sports activities may be broadly classified into events that require great expressions of strength

256 and power (e.g., Olympic-style weightlifting, powerlifting, and throwing events in track and

257 field) and those tremendous demanding endurance (e.g., marathon run and triathlon) (1). In

258 addition, many activities like middle-distance sprint running and team and combat sports,

259 which are characterized by intermittent efforts, require combinations of high levels of strength

260 and power, combined with a well-developed aerobic capacity for peak performance (1).Table

26110 summarizes the skeletal muscle functional proprieties definition and exercises/training

262 methods used for their development.

\section{Please, Insert Table 10 About Here}

264 In addition to physical training, literature presents several adaptations and health benefits of

265 endurance and strength and power training that may also be used in the proper classification of

266 training stimulus (2). Our intention with this article was not to disqualify the studies, physical

267 training programs, and the practice of the physical activities, but to provide the correct 
268 definitions of terms and concepts to allow proper communication between students, coaches,

269 athletes, and sports scientists.

\section{$270 \quad 7 \quad$ Conflict of Interest}

271 The authors declare that the research was conducted in the absence of any commercial or

272 financial relationships that could be construed as a potential conflict of interest.

\section{$273 \quad 8 \quad$ Author Contributions}

274 BNI conceived the idea, performed the initial data collection, wrote the first draft, worked on

275 all drafts, and formatted the manuscript for submission. APS, MM, CPCS, BVC, DJO, and

276 GRM helped develop the main idea and draft the paper. All authors read and approved the last

277 version of the manuscript.

2789 Funding

279 No sources of funding were used to assist in the preparation of this article.

$280 \quad 10 \quad$ References

281 1. Nader GA. Concurrent strength and endurance training: from molecules to man. Med

282 Sci Sports Exerc (2006) 38(11):1965-70. Epub 2006/11/11. doi:

283 10.1249/01.mss.0000233795.39282.33. PubMed PMID: 17095931.

284 2. Egan B, Zierath JR. Exercise metabolism and the molecular regulation of skeletal

285 muscle adaptation. Cell Metab (2013) 17(2):162-84. Epub 2013/02/12. doi:

286 10.1016/j.cmet.2012.12.012. PubMed PMID: 23395166.

287 3. Hughes DC, Ellefsen S, Baar K. Adaptations to Endurance and Strength Training. Cold

288 Spring Harb Perspect Med (2018) 8(6). Epub 2017/05/12. doi: 10.1101/cshperspect.a029769.

289 PubMed PMID: 28490537; PubMed Central PMCID: PMCPMC5983157.

2904 4. Winter EM, Fowler N. Exercise defined and quantified according to the Systeme

291 International d'Unites. J Sports Sci (2009) 27(5):447-60. Epub 2009/03/03. doi: 292 10.1080/02640410802658461. PubMed PMID: 19253082.

293 5. Knuttgen HG. Force, work, power, and exercise. Med Sci Sports (1978) 10(3):227-8. 294 Epub 1978/01/01. PubMed PMID: 723517.

295 6. Knuttgen HG, Komi PV. Basic Considerations for Exercise. Strength and Power in 296 Sport. (2003). p. 3-7. 
297 7. Knudson DV, Magnusson P, McHugh M. Current Issues in Flexibility Fitness.

298 President's Council on Physical Fitness and Sports Research Digest (2000).

299 8. Cormie P, McGuigan MR, Newton RU. Developing maximal neuromuscular power:

300 part 2 - training considerations for improving maximal power production. Sports Med (2011)

301 41(2):125-46. Epub 2011/01/20. doi: 10.2165/11538500-000000000-00000. PubMed PMID:

30221244105.

303 9. Granata C, Jamnick NA, Bishop DJ. Principles of Exercise Prescription, and How They

304 Influence Exercise-Induced Changes of Transcription Factors and Other Regulators of

305 Mitochondrial Biogenesis. Sports Med (2018) 48(7):1541-59. Epub 2018/04/21. doi:

306 10.1007/s40279-018-0894-4. PubMed PMID: 29675670.

307 10. Nuzzo JL. The Case for Retiring Flexibility as a Major Component of Physical Fitness.

308 Sports Med (2020) 50(5):853-70. Epub 2019/12/18. doi: 10.1007/s40279-019-01248-w.

309 PubMed PMID: 31845202.

310 11. Baar K. Nutrition and the adaptation to endurance training. Sports Med (2014) 44 Suppl

311 1:S5-12. Epub 2014/05/06. doi: 10.1007/s40279-014-0146-1. PubMed PMID: 24791912;

312 PubMed Central PMCID: PMCPMC4008803.

313 12. Cormie P, McGuigan MR, Newton RU. Developing maximal neuromuscular power:

314 Part 1--biological basis of maximal power production. Sports Med (2011) 41(1):17-38. Epub

315 2010/12/15. doi: 10.2165/11537690-000000000-00000. PubMed PMID: 21142282.

316 13. Åstrand PO. Endurance Sports. Endurance in Sport (2000):9-15.

317 14. Buchheit M, Laursen PB. High-intensity interval training, solutions to the programming

318 puzzle: Part I: cardiopulmonary emphasis. Sports Med (2013) 43(5):313-38. Epub 2013/03/30.

319 doi: 10.1007/s40279-013-0029-x. PubMed PMID: 23539308.

320 15. Ide BN, Marocolo M, Santos CP, Silva BVC, Silvatti AP, Simim MAdM, et al. A

321 Commentary on:"'You're Only as Strong as Your Weakest Link': A Current Opinion about the

322 Concepts and Characteristics of Functional Training". Frontiers in Physiology (2021):1854.

323 doi: 10.3389/fphys.2021.744144.

324 16. Wirth K, Hartmann H, Mickel C, Szilvas E, Keiner M, Sander A. Core Stability in

325 Athletes: A Critical Analysis of Current Guidelines. Sports Med (2017) 47(3):401-14. Epub

326 2016/08/01. doi: 10.1007/s40279-016-0597-7. PubMed PMID: 27475953.

327 17. Fleck SJ, Kraemer W. Designing resistance training programs. Fourth ed: Human 328 Kinetics (2014).

329 18. Boyle M. Functional training for sports: superior conditioning for today's athlete:

330 Human Kinetics (2004).

331 19. Boyle M. New functional training for sports: Human Kinetics (2016).

332

20. Suchomel TJ, Nimphius S, Bellon CR, Stone MH. The Importance of Muscular Strength: Training Considerations. Sports Med (2018) 48(4):765-85. Epub 2018/01/27. doi: 10.1007/s40279-018-0862-z. PubMed PMID: 29372481.

21. Da Silva-Grigoletto ME, Neto EP, Behm DG, Loenneke JP, La Scala Teixeira CV. Functional Training and Blood Flow Restriction: A Perspective View on the Integration of Techniques. Front Physiol (2020) 11:817. Epub 2020/08/28. doi: 10.3389/fphys.2020.00817. PubMed PMID: 32848818; PubMed Central PMCID: PMCPMC7412632.

22. La Scala Teixeira CV, Evangelista AL, Novaes JS, Da Silva Grigoletto ME, Behm DG. "You're Only as Strong as Your Weakest Link": A Current Opinion about the Concepts and Characteristics of Functional Training. Front Physiol (2017) 8:643. Epub 2017/09/16. doi: 10.3389/fphys.2017.00643. PubMed PMID: 28912728; PubMed Central PMCID: PMCPMC5582309.

23. Fyfe JJ, Bishop DJ, Stepto NK. Interference between concurrent resistance and endurance exercise: molecular bases and the role of individual training variables. Sports Med 
346 (2014) 44(6):743-62. Epub 2014/04/15. doi: 10.1007/s40279-014-0162-1. PubMed PMID: 34724728927.

348 24. Knapik JJ. Extreme Conditioning Programs: Potential Benefits and Potential Risks. $J$ Spec Oper Med (2015) 15(3):108-13. Epub 2015/09/12. PubMed PMID: 26360365. 25. Haff GG, Nimphius S. Training Principles for Power. Strength \& Conditioning Journal (2012) 34(6):2-12. doi: 10.1519/SSC.0b013e31826db467. PubMed PMID: 00126548201212000-00002.

26. Haff GG, Stone MH. Methods of Developing Power With Special Reference to Football Players. Strength \& Conditioning Journal (2015) 37(6):2-16. doi: 10.1519/ssc.0000000000000153. PubMed PMID: 00126548-201512000-00002.

27. Thompson WR. Worldwide Survey of Fitness Trends for 2021. ACSM'S Health \& Fitness Journal (2021) 25(1):10-9. doi: 10.1249/fit.0000000000000631. PubMed PMID: 00135124-202101000-00006.

28. Tibana RA, Sousa NMF, Prestes J, Feito Y, Ferreira CE, Voltarelli FA. Monitoring Training Load, Well-Being, Heart Rate Variability, and Competitive Performance of a Functional-Fitness Female Athlete: A Case Study. Sports (Basel) (2019) 7(2):35. Epub 2019/02/13. doi: 10.3390/sports7020035. PubMed PMID: 30744103; PubMed Central PMCID: PMCPMC6409702.

29. Garber CE, Blissmer B, Deschenes MR, Franklin BA, Lamonte MJ, Lee IM, et al. American College of Sports Medicine position stand. Quantity and quality of exercise for developing and maintaining cardiorespiratory, musculoskeletal, and neuromotor fitness in apparently healthy adults: guidance for prescribing exercise. Med Sci Sports Exerc (2011) 43(7):1334-59. Epub 2011/06/23. doi: 10.1249/MSS.0b013e318213fefb. PubMed PMID: 21694556.

30. Shephard RJ. Semantic and Physiological Definitions. Endurance in Sport. (2000). p. 3-8.

31. McLaughlin EC, El-Kotob R, Chaput JP, Janssen I, Kho ME, Poitras VJ, et al. Balance and functional training and health in adults: an overview of systematic reviews. Appl Physiol Nutr Metab (2020) 45(10 (Suppl. 2)):S180-S96. Epub 2020/10/16. doi: 10.1139/apnm-20200279. PubMed PMID: 33054334.

32. American College of Sports M, Chodzko-Zajko WJ, Proctor DN, Fiatarone Singh MA, Minson CT, Nigg CR, et al. American College of Sports Medicine position stand. Exercise and physical activity for older adults. Med Sci Sports Exerc (2009) 41(7):1510-30. Epub 2009/06/12. doi: 10.1249/MSS.0b013e3181a0c95c. PubMed PMID: 19516148.

33. Martuscello JM, Nuzzo JL, Ashley CD, Campbell BI, Orriola JJ, Mayer JM. Systematic review of core muscle activity during physical fitness exercises. J Strength Cond Res (2013) 27(6):1684-98. Epub 2013/04/02. doi: 10.1519/JSC.0b013e318291b8da. PubMed PMID: 23542879 .

34. Da Silva-Grigoletto ME, Mesquita MMA, Aragão-Santos JC, Santos MS, ResendeNeto AG, de Santana JM, et al. Functional Training Induces Greater Variety and Magnitude of Training Improvements than Traditional Resistance Training in Elderly Women. Journal of sports science \& medicine (2019) 18(4):789-97. Epub 2019/12/13. PubMed PMID: 31827364; PubMed Central PMCID: PMCPMC6873136.

35. Stenger L. What Is Functional/Neuromotor Fitness? ACSM'S Health \& Fitness Journal (2018) 22(6):35-43. doi: 10.1249/fit.0000000000000439. PubMed PMID: 00135124201811000-00010.

36. World Health Organization. International classification of functioning, disability and health : ICF. Geneva, Switzerland: World Health Organization (2013). 
394 37. Girard O, Mendez-Villanueva A, Bishop D. Repeated-sprint ability - part I: factors 395 contributing to fatigue. Sports Med (2011) 41(8):673-94. Epub 2011/07/26. doi: 396 10.2165/11590550-000000000-00000. PubMed PMID: 21780851.

397 38. Lajoso-Silva N, Bezerra P, Silva B, Carral JMC. Functional Training in Portuguese 398 Firefighters: Impact of Functional Training With or Without Personal Protective Equipment. 399 Journal of occupational and environmental medicine (2021) 63(4):e169-e76. Epub 2021/03/27. doi: 10.1097/JOM.0000000000002141. PubMed PMID: 33769402.

39. Gali JC, Fadel GW, Marques MF, Almeida TA, Gali JC, Faria FAS. The New Injuries' Risk after Acl Reconstruction Might Be Reduced with Functional Training. Acta ortopedica brasileira (2021) 29(1):21-5. Epub 2021/04/03. doi: 10.1590/1413-785220212901240903. PubMed PMID: 33795964; PubMed Central PMCID: PMCPMC7976865.

40. Farrokhian S, Alamdarloo GH, Asadmanesh E. The effectiveness of functional training on impulsiveness of females with intellectual disability. Health psychology research (2020) 8(3):9116. Epub 2021/02/09. doi: 10.4081/hpr.2020.9116. PubMed PMID: 33553788; PubMed Central PMCID: PMCPMC7859959.

41. Cheng TTJ, Mansor A, Lim YZ, Hossain Parash MT. Injury Incidence, Patterns, and Risk Factors in Functional Training Athletes in an Asian Population. Orthop J Sports Med (2020) 8(10):2325967120957412. Epub 2020/11/17. doi: 10.1177/2325967120957412. PubMed PMID: 33195710; PubMed Central PMCID: PMCPMC7605001.

42. Peterson JA. Ten Nice-to-Know Facts About Functional Training. ACSM'S Health \& Fitness Journal (2017) 21(3):52. doi: 10.1249/fit.0000000000000301. PubMed PMID: 00135124-201705000-00015.

43. Aragao-Santos JC, de Resende-Neto AG, Da Silva-Grigoletto ME. Different types of functional training on the functionality and quality of life in postmenopausal women: a randomized and controlled trial. J Sports Med Phys Fitness (2020) 60(9):1283-90. Epub 2020/10/31. doi: 10.23736/S0022-4707.20.10995-2. PubMed PMID: 33124792.

44. Feito Y, Heinrich KM, Butcher SJ, Poston WSC. High-Intensity Functional Training (HIFT): Definition and Research Implications for Improved Fitness. Sports (Basel) (2018) 6(3). Epub 2018/08/09. doi: 10.3390/sports6030076. PubMed PMID: 30087252; PubMed Central PMCID: PMCPMC6162410.

45. Teixeira RV, Batista GR, Mortatti AL, Dantas PMS, Cabral B. Effects of Six Weeks of High-Intensity Functional Training on Physical Performance in Participants with Different Training Volumes and Frequencies. Int J Environ Res Public Health (2020) 17(17). Epub 2020/08/23. doi: 10.3390/ijerph17176058. PubMed PMID: 32825378; PubMed Central PMCID: PMCPMC7503715.

46. Gomes JH, Mendes RR, Franca CS, Da Silva-Grigoletto ME, Pereira da Silva DR, Antoniolli AR, et al. Acute leucocyte, muscle damage, and stress marker responses to highintensity functional training. PLoS One (2020) 15(12):e0243276. Epub 2020/12/04. doi: 10.1371/journal.pone.0243276. PubMed PMID: 33270727; PubMed Central PMCID: PMCPMC7714345.

47. Browne JD, Carter R, Robinson A, Waldrup B, Zhang G, Carrillo E, et al. Not All HIFT Classes Are Created Equal: Evaluating Energy Expenditure and Relative Intensity of a HighIntensity Functional Training Regimen. Int J Exerc Sci (2020) 13(4):1206-16. Epub 2020/10/13. PubMed PMID: 33042371; PubMed Central PMCID: PMCPMC7523891.

48. Ben-Zeev T, Hirsh T, Weiss I, Gornstein M, Okun E. The Effects of High-intensity Functional Training (HIFT) on Spatial Learning, Visual Pattern Separation and Attention Span in Adolescents. Front Behav Neurosci (2020) 14:577390. Epub 2020/10/24. doi: 10.3389/fnbeh.2020.577390. PubMed PMID: 33093827; PubMed Central PMCID: PMCPMC7521200. 
443 49. Ben-Zeev T, Okun E. High-Intensity Functional Training: Molecular Mechanisms and 444 Benefits. Neuromolecular Med (2021) 23(3):335-8. Epub 2021/01/03. doi: 10.1007/s12017445 020-08638-8. PubMed PMID: 33386577.

446

447 


\section{$448 \quad 11 \quad$ Figure Legends}

449 Figure 1. Summary of adaptations/benefits induced by FT, HIFT and FF training programs.

450 *Other adaptations cited are neuromuscular control, joint mobility and stability, central 451 stability, trunk alignment and lower limb joint; conditional and coordinative capacities; ability 452 to perform the ADL at home, work, or play without undue risk of injury or fatigue; jump ability; 453 gait speed and quality of life.

454 Figure 2. Summary of the exercises/training methods employed in FT, HIFT and FF training 455 programs. 
$\begin{array}{lll}456 & 12 & \text { Tables }\end{array}$

457 Table 1. FT definitions.
Reference
Functional Training Definition

\begin{tabular}{cc}
\hline $\begin{array}{c}\text { Lajoso-Silva et } \\
\text { al. (38) }\end{array}$ & FT utilizes multi-articular movements to improve balance, increase muscular power and strength, and enhance conditional and \\
coordinative capacities.
\end{tabular}

McLaughlin, E.

C. et al. (31)

Functional training uses functional activities as the training stimulus and is based on the theoretical concept of task specificity.

Farrokhzad, S. et al. (40)

FT is a set of sports activities that are based on daily routine activities such as walking, climbing up stairs and going down, getting up and sitting down and move light things. FT was focused improving physical fitness such as endurance, strength, flexibility, and balance.

Da Silva- $\quad$ FT involves resistance training and associated techniques to develop strength, as well as balance, motor coordination, power, and Grigoletto, M. E. muscle endurance, increasing the ability of individuals to execute ADL, whether they be simpler tasks of daily living or more et al. (21) complex athletic maneuvers.

Cheng, T. T. J. et A form of training that uses modular movements that involve the recruitment of multiple muscle groups, FT is the only program al. (41) that combines weightlifting, gymnastics, and metabolic conditioning in one continuous session.

Peterson, James FT is designed to enhance the ability of exercisers to meet the demands of performing a wide range of ADL at home, work, or A. (42) play without undue risk of injury or fatigue.

\begin{tabular}{cc}
\hline $\begin{array}{l}\text { Aragão-Santos, } \\
\text { J. C. et al. (43) is a multicomponent training method, which stimulates different physical capacities in the same session. This training method } \\
\text { can be carried out with an emphasis on traditional exercises such as squats to improve the strength of lower limbs (element-based }\end{array}$ \\
\hline
\end{tabular}


functional training) or using exercises more like daily activities such as carrying actions or sit and get up from the floor (taskspecific-based functional training).

La Scala The development of different physical capacities in an integrated and balanced manner to provide autonomy, efficiency and

Teixeira, C. V. et safety during activities related to ADLs, work and/or sports. For this purpose, FT uses strength exercises generally characterized al. (22) by integrated, multi-joint/multi-segment, asymmetrical, multi-planes, acyclic, intermittent, speedy, and unstable movements that emphasize core stability.

\begin{tabular}{|c|c|}
\hline $\begin{array}{c}\text { Fleck and } \\
\text { Kraemer (17) }\end{array}$ & $\begin{array}{l}\text { The training that is meant to increase performance in some type of functional task, such as activities of daily living or tests } \\
\text { related to athletic performance. FT could refer to virtually any type of training meant to increase motor performance. }\end{array}$ \\
\hline Boyle (19) & $\begin{array}{c}\text { Functional training on the other hand uses many concepts developed by sport coaches to train speed, strength, and power to } \\
\text { improve sport performance and reduce incidence of injury. }\end{array}$ \\
\hline Boyle (18) & $\begin{array}{l}\text { Functional training can therefore be described as purposeful training. In fact, functional training is more accurately represented } \\
\text { as "sports-general" training. Functional training is a system that encourages the training of balance and the balancing of training. } \\
\text { It is characterized by actions such as squatting and lunging or pushing and pulling. Functional training is best described as a } \\
\text { continuum of exercises that teach athletes to handle their own body weight in all planes of movement. }\end{array}$ \\
\hline
\end{tabular}

ADLs: activities of daily living; FT: functional training; HIIT: high-intensity interval training. 


\section{Reference}

\section{HIFT Definition}

Feito et al. A training style [or program] that incorporates a variety of functional movements, performed at high intensity [relative to an (44) individual's ability], and designed to improve parameters of general physical fitness (e.g., cardiovascular endurance, strength, body composition, flexibility, etc.) and performance (e.g., agility, speed, power, strength, etc.).
HIFT is a modality characterized by presenting high volumes and training intensities with constantly varied exercises with or
Teixeira, R. without any recovery interval between the series. HIFT training sessions consist of Olympic weightlifting exercises (e.g., clean V. et al. and jerk, snatch), gymnastics (e.g., lunges and pull-ups) and metabolic conditioning (e.g., running and rowing). In addition to (45) the diversity of functional movements performed in high intensity, HIFT aims to improve physical conditioning variables (i.e., strength, body composition, among others) and performance (i.e., speed, power, among others).

Gomes, J.
H. et al.

Exercise regimen characterized by high intensity, constant variation, and functional movement is often performed in rapid,

(46) et al. successive repetition with limited or no recovery time. HIFT is based on the concept of increased work capacity over time
using a variety of exercise modalities, including mono-structural (e.g., running, rowing, etc.), as well as body weight

movements (e.g., squats, push-ups, etc.) and weightlifting derivatives (e.g., snatch, shoulder press, deadlift, etc.).

\section{Browne, J. \\ D. et al.}

HIFT incorporates many of the same principles as HIIT, including the relatively high work-to-rest intervals. However, HIFT training goes further and weaves multimodal resistance training with cardiovascular exercises. HIFT consists of a variable series of these functional whole-body exercises with little rest, while HIIT consists of unimodal, single-plane movements with distinct periods of low-intensity activity or rest.

Ben-Zeev, T. et al. (48)
HIFT is a form of physical activity that can be modified to any fitness level and elicits greater muscle recruitment than repetitive aerobic exercises, thereby improving cardiovascular endurance, strength, and flexibility. HIFT emphasizes functional,
multi-joint movements via HIIT and muscle-strengthening exercises. 
Table 3. Functional fitness definitions.

\section{Reference}

\section{Functional Fitness definition}

Thompson A trend toward using strength training to improve balance, coordination, muscular strength, and endurance to improve activities $(27,28) \quad$ of daily living typically for older adults and in clinical populations.

A relatively new form of exercise (also known as HIFT; extreme conditioning programs) that is currently being marketed to a
wibana et
$\begin{gathered}\text { wide range of active (athletes, military) and inactive populations. The competitive functional fitness (e.g., CrossFit }{ }^{\mathbb{R}} \text { ) often } \\ \text { al. (28) }\end{gathered}$

\section{Peterson, \\ James A.} exercises, sprints, and flexibility mixed to achieve a high global performance. 
464 Table 4. Adaptations/benefits provided by FT programs.

Reference

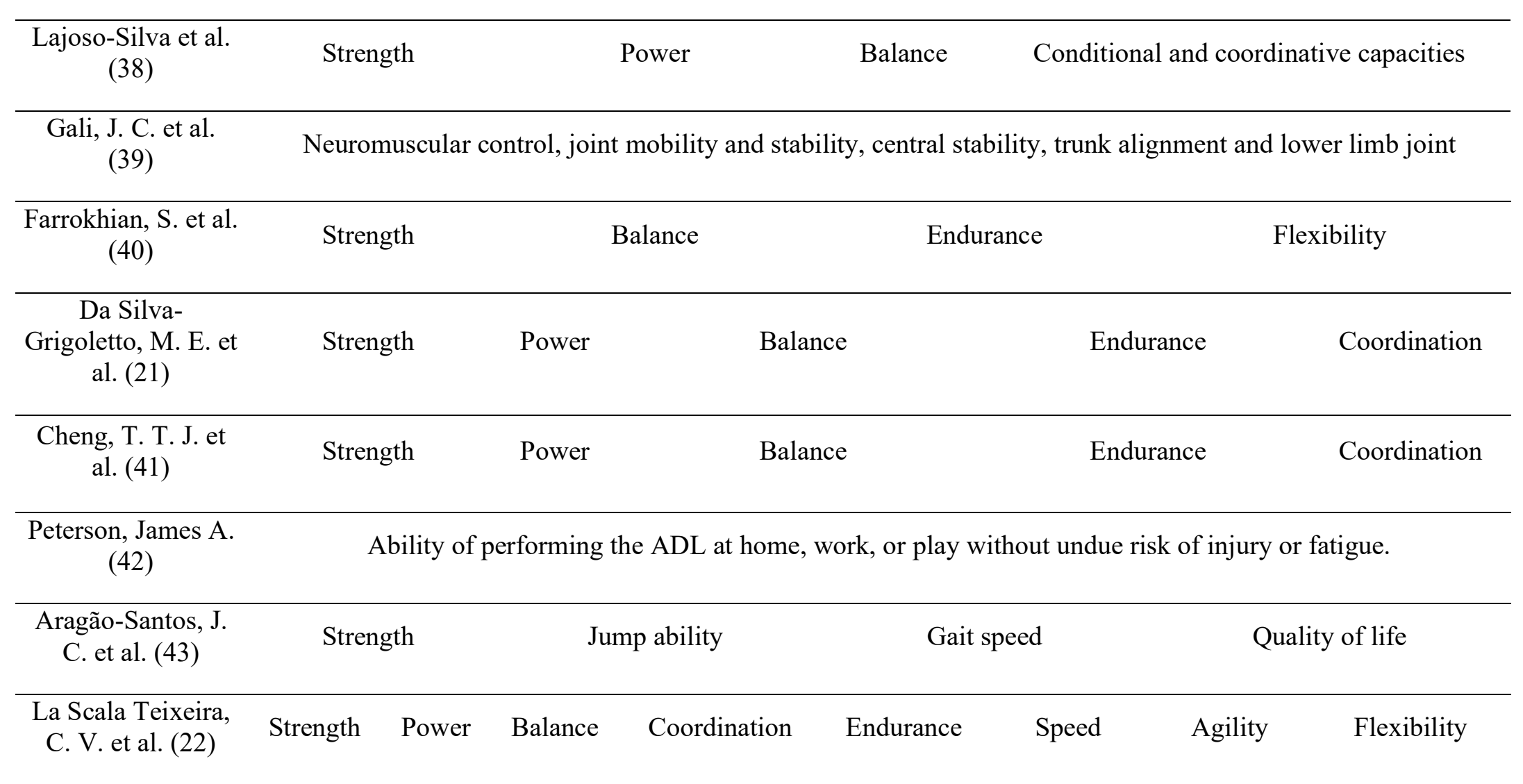


467 Table 5. Adaptations/benefits provided by HIFT programs.

\begin{tabular}{|c|c|c|c|c|c|c|c|}
\hline Reference & \multicolumn{7}{|c|}{ HIFT adaptations/benefits } \\
\hline Feito et al. (44) & Strength & Power & Flexibility & Speed & Agility & Endurance & $\begin{array}{c}\text { Body } \\
\text { composition }\end{array}$ \\
\hline $\begin{array}{l}\text { Teixeira, R. V. et } \\
\text { al. (45) }\end{array}$ & \multicolumn{2}{|c|}{ Strength } & Power & \multicolumn{2}{|c|}{ Speed } & \multicolumn{2}{|c|}{ Body composition } \\
\hline $\begin{array}{c}\text { Gomes, J. H. et al. } \\
\text { (46) }\end{array}$ & Strength & Power & Flexibility & Speed & Agility & Endurance & $\begin{array}{c}\text { Body } \\
\text { composition }\end{array}$ \\
\hline $\begin{array}{l}\text { Ben-Zeev, T. et } \\
\text { al. (49) }\end{array}$ & Strength & Power & Flexibility & Speed & Agility & Endurance & $\begin{array}{c}\text { Body } \\
\text { composition }\end{array}$ \\
\hline
\end{tabular}

468

469 Table 6. Adaptations/benefits provided by functional fitness training programs.

\begin{tabular}{|c|c|c|c|c|}
\hline \multirow{2}{*}{$\begin{array}{c}\text { Reference } \\
\text { Thompson (27) }\end{array}$} & \multicolumn{4}{|c|}{ Functional fitness adaptations/benefits } \\
\hline & Strength & Balance & Coordination & Endurance \\
\hline Tibana et al. (28) & \multicolumn{4}{|c|}{ High global performance } \\
\hline
\end{tabular}

470

471 
472 Table 7. Exercises and employed in FT programs.

\begin{tabular}{|c|c|c|c|c|}
\hline Reference & \multicolumn{4}{|c|}{ Exercises employed in FT programs } \\
\hline Lajoso-Silva et al. (38) & \multicolumn{4}{|c|}{ Multi-articular movements } \\
\hline Gali, J. C. et al. (39) & $\begin{array}{c}\text { Olympic } \\
\text { weightlifting }\end{array}$ & $\begin{array}{l}\text { Strength } \\
\text { exercises }\end{array}$ & Plyometrics & Endurance training \\
\hline $\begin{array}{l}\text { McLaughlin, E. C. et al. } \\
(31)\end{array}$ & \multicolumn{4}{|c|}{ Functional activities } \\
\hline Farrokhian, S. et al. (40) & $\begin{array}{l}\text { Daily routine } \\
\text { activities }\end{array}$ & Walking & $\begin{array}{l}\text { Climbing up stairs } \\
\text { and going down }\end{array}$ & $\begin{array}{l}\text { Getting up and sitting } \\
\text { down and move light } \\
\text { things }\end{array}$ \\
\hline $\begin{array}{c}\text { Da Silva-Grigoletto, M. E. } \\
\text { et al. (21) }\end{array}$ & \multicolumn{4}{|c|}{ Resistance training and associated techniques } \\
\hline Cheng, T. T. J. et al. (41) & $\begin{array}{c}\text { Olympic } \\
\text { weightlifting }\end{array}$ & Gymnastics & \multicolumn{2}{|c|}{ Modular movements } \\
\hline $\begin{array}{c}\text { Aragão-Santos, J. C. et al. } \\
\text { (43) }\end{array}$ & \multicolumn{2}{|c|}{ Squats } & \multicolumn{2}{|c|}{ Daily routine activities } \\
\hline $\begin{array}{c}\text { La Scala Teixeira, C. V. et } \\
\text { al. (22) }\end{array}$ & \multicolumn{4}{|c|}{ Strength exercises } \\
\hline
\end{tabular}


475 Table 8. Exercises employed in high-intensity functional training programs.

\begin{tabular}{|c|c|c|c|c|c|c|c|}
\hline Reference & \multicolumn{7}{|c|}{ HIFT Exercises/training methods employed } \\
\hline Feito et al. (44) & \multicolumn{7}{|c|}{ Functional movements } \\
\hline $\begin{array}{l}\text { Teixeira, R. V. } \\
\text { et al. (45) }\end{array}$ & $\begin{array}{l}\text { Functional } \\
\text { movements }\end{array}$ & $\begin{array}{c}\text { Olympic } \\
\text { weightlifting }\end{array}$ & Running & Rowing & Gymnastics & $\begin{array}{r}\text { Const } \\
\text { e }\end{array}$ & $\begin{array}{l}\text { y varied } \\
\text { ises }\end{array}$ \\
\hline $\begin{array}{l}\text { Gomes, J. H. et } \\
\text { al. (46) }\end{array}$ & $\begin{array}{l}\text { Functional } \\
\text { movements }\end{array}$ & $\begin{array}{c}\text { Olympic } \\
\text { weightlifting }\end{array}$ & Running & Rowing & $\begin{array}{l}\text { Body weight } \\
\text { movements }\end{array}$ & Squats & Push-ups \\
\hline $\begin{array}{l}\text { Browne, J. D. } \\
\text { et al. (47) }\end{array}$ & $\begin{array}{l}\text { Functional } \\
\text { movements }\end{array}$ & \multicolumn{3}{|c|}{ Cardiovascular exercises } & \multicolumn{3}{|c|}{ Resistance training } \\
\hline $\begin{array}{c}\text { Ben-Zeev, T. } \\
\text { et al. (49) }\end{array}$ & \multicolumn{4}{|c|}{ Functional movements } & \multicolumn{3}{|c|}{ Strength exercises } \\
\hline
\end{tabular}

476

477 Table 9. Exercises employed in functional fitness training programs.

\begin{tabular}{|c|c|c|c|c|}
\hline Reference & \multicolumn{4}{|c|}{ Functional fitness exercises/training methods employed } \\
\hline Thompson (27) & \multicolumn{4}{|c|}{ Strength training } \\
\hline $\begin{array}{l}\text { Tibana et al. } \\
\text { (28) }\end{array}$ & $\begin{array}{c}\text { Olympic } \\
\text { weightlifting }\end{array}$ & Gymnastics & $\begin{array}{c}\text { Cardiovascular } \\
\text { exercises }\end{array}$ & Sprints \\
\hline
\end{tabular}


Table 10. Skeletal muscle adaptations and exercises/training methods.

\begin{tabular}{|c|c|c|}
\hline & Definition & $\begin{array}{l}\text { Exercises/training methods used } \\
\text { in the training programs }\end{array}$ \\
\hline Strength & $\begin{array}{l}\text { The force or torque can be developed by } \\
\text { the muscles performing a particular joint } \\
\text { movement (e.g., elbow flexion, knee } \\
\text { extension) (6). }\end{array}$ & $\begin{aligned} \rightarrow & \text { Traditional resistance } \\
& \text { training. } \\
\rightarrow & \text { Ballistic exercises. } \\
\rightarrow & \text { Plyometrics. }\end{aligned}$ \\
\hline Power & $\begin{array}{l}\text { The rate of performing work; the } \\
\text { derivative of work concerning time; the } \\
\text { product of force and velocity (6). }\end{array}$ & $\begin{aligned} \rightarrow & \text { Olympic-style } \\
& \text { weightlifting. } \\
\rightarrow & \text { Sprints and resisted sprints. }\end{aligned}$ \\
\hline Endurance & $\begin{array}{l}\text { The ability to maintain either a specific } \\
\text { isometric force, or a specific power level, } \\
\text { involving combinations of concentric and } \\
\text { eccentric muscular actions (4). }\end{array}$ & $\begin{aligned} \rightarrow & \text { Low- and moderate- } \\
& \text { intensity continuous } \\
& \text { exercise. } \\
\rightarrow & \text { Interval training variations } \\
& \text { (e.g., HIIT, RST, and SIT). }\end{aligned}$ \\
\hline Flexibility & $\begin{array}{l}\text { The intrinsic property of body tissues } \\
\text { determines the range of motion } \\
\text { achievable without injury (7). }\end{array}$ & $\begin{aligned} \rightarrow & \text { Static, dynamic/ballistic } \\
& \text { stretching. } \\
\rightarrow & \text { Proprioceptive } \\
& \text { neuromuscular facilitation } \\
& \text { stretching. }\end{aligned}$ \\
\hline
\end{tabular}

HIIT: High-intensity interval training; RST: repeated sprints training; SIT: sprint interval training. 